\title{
Introduction Paper of the Special Issue on Gap Junctions in Honor of Ross Johnson
}

\author{
Paul D. Lampe · Dale W. Laird
}

Published online: 8 July 2012

(C) Springer Science+Business Media, LLC 2012

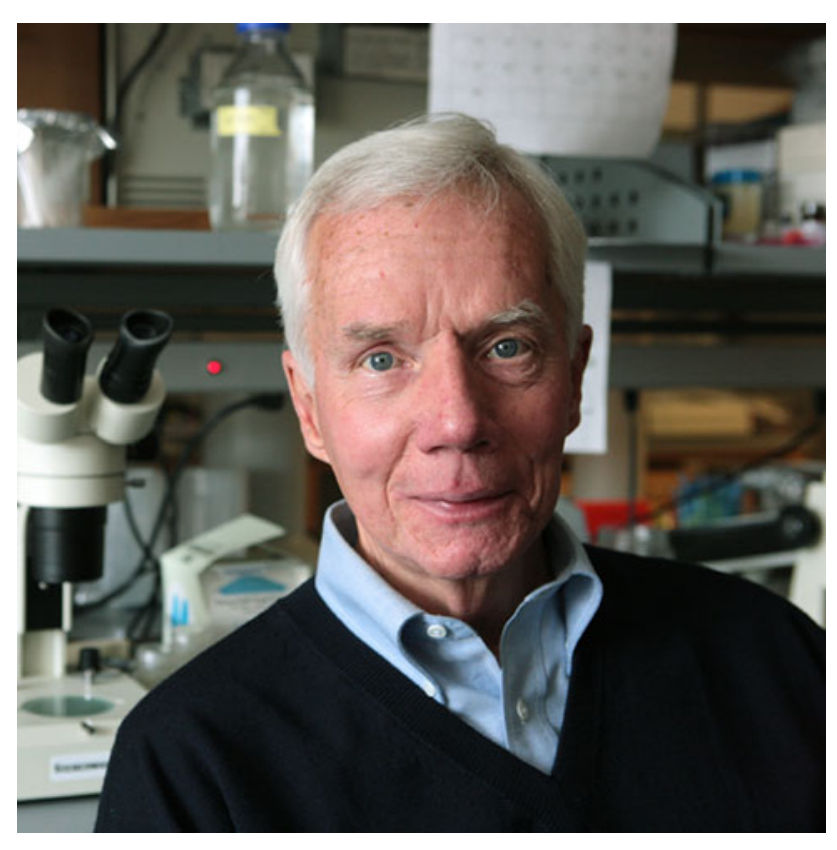

On a hot Saturday evening in August of 2009, the gap junction community gathered at the Hilton in Sedona, AZ in anticipation of the biennial International Gap Junction Conference. This meeting was particularly special as it was an opportunity to honor and pay tribute to one of the long

P. D. Lampe $(\square)$

Fred Hutchinson Cancer Research Center, 1100 Fairview Avenue North, M5C800, Box 19024, Seattle, WA 98109, USA e-mail: plampe@fhcrc.org

D. W. Laird

Department of Anatomy and Cell Biology, Western University, London, ON, Canada

e-mail: dale.laird@schulich.uwo.ca time leaders and life-time contributors to the field, Dr. Ross Johnson. After Dr. Paul Lampe recapped Ross' notable and seminal contributions to the field, Ross spoke elegantly and humbly about his joy of science and the love of this community. Ross was accompanied by his lovely wife Esther, who often joined him in his travels and who has become endeared to the community in her own right. Phrases like "he is one of the really good guys", "I know he respects my work" and "he gives generously of his time" echoed in the halls of the Sedona meeting as colleagues recounted their interactions with Ross over four decades. It is a privilege and honor for us to know Ross and to spearhead and act as guest editors for this special Journal of Membrane Biology issue dedicated equally to Ross' achievements in science and to the mentorship and friendship he has extended to many of us in the field. A testament to Ross' impact on the community was evidenced by the fact that over $95 \%$ of the colleagues asked to contribute to this issue agreed without hesitation and with comments like "I would only do it for Ross", "Definitely, for Ross" and "Count me in". To all of you, we say thank you for your timely contributions. We also wish to express our gratitude and thanks to Dr. Tom Woolf, Editorin-Chief, for supporting this initiative and for taking a leading role in seeing that this endeavor is executed with the highest level of professionalism. Finally, to Dr. Jan Hoh, Ross' long-time friend and ours as well, we also say thanks for seeding this idea with Tom.

Ross began his academic career at Augustana College from which he graduated with a BA before moving to Iowa State University, where he obtained a NIH predoctoral Fellowship to complete his PhD. It was here that he fell in love with cell biology. Success came quickly for Ross as he was immediately recruited as an Assistant Professor in the Department of Zoology at the University of Minnesota 
(later joining Genetics and Cell Biology after a reorganization), where he would spend his entire scientific career and rise through the ranks to Professor and Head of the Department. It was during his early years as an independent investigator that Ross engaged in a newly emerging field called gap junction biology. At the outset, Ross chose to establish formidable collaborations with two pioneers of the field, Minnesota colleague Dr. Judd Sheridan, who introduced Ross to gap junctions, and Dr. Jean-Paul Revel. Jean-Paul, who was instrumental in naming gap junctions, has frequently been recognized as the first to use electron microscopy to describe their distinctive structure, although the widespread distribution of gap junctions was under appreciated in these early days. Together with Judd, Ross entered the gap junction literature in 1971 with a splash as his first paper was published in Science and depicted gap junctions in hepatoma cells, indicating that junctions were not absent in all cancer cells as some believed at that time. Later Ross' team used freeze-fracture electron microscopy to clearly show that gap junctions could form between cells of different types, further expanding the versatility and importance of gap junctions in tissue biology. However, with Jean-Paul, Ross reported in Science that there were limitations as to where gap junctions would form, noting that they were not observed in Dictostelium discoideum (slime molds).

Throughout his career, one of the most prominent research themes developed by Ross and his team was related to the mechanisms of gap junction assembly. Ross and Judd coined the term "formation plaque" to describe the specialized membrane areas present in both opposed cells at the early stages of gap junction assembly. This theme persisted from an early paper in 1974 published in Proceedings of the National Academy of Science to his most recent paper published in the Molecular Biology of the Cell in 2012, the latter with microscopy by Dr. Jim Reynhout that was pivotal. These papers book-ended nearly 40 years of studies that highlight the power of high resolution freeze-fracture electron microscopy and, more recently, freeze-fracture replica immunolabeling. In this special issue, Dr. Rash, another collaborator of Ross' highlights novel insights that can be deduced from these morphological studies. In 1976 Ross used his sabbatical year to study with his long-time friend Jean-Paul Revel at Caltech and it was there that he started to complement his cell biological and morphological approaches with cell fractionation and biochemical studies. In those days, the connexin proteins had not yet been identified and candidate proteins that constituted gap junction channels were constantly being evaluated.

As Ross entered the 80's he continued to expand the scope of his laboratory by establishing new collaborations. He turned his eye to the lens (no pun intended) as a rich source of gap junction proteins, and had productive collaborations with Dr. Charles Louis. Together with Dr. Sue Menko, he developed methods to culture lens fiber cells that are still used today and are featured in Dr. Linda Musil's article in this issue. Together with Dr. Elliot Hertzberg, in 1987 Ross co-organized the first ever International Gap Junction Conference (IGJC) at Asilomar, CA. With Ross' guidance this meeting evolved into the primary conference series serving the field that would be held every two years to this day. During this decade Ross also began to mentor Dr. Paul Lampe who brought his considerable biochemical skills to the ever expanding arsenal of approaches used in Ross' laboratory. Together as friends and colleagues, they built on the work of Dr. Keith Johnson, a former student in the lab, and pioneered studies on the phosphorylation of lens MIP. They then applied these approaches to phosphorylation events associated with the newly emerging connexin family of gap junction proteins. Importantly, Ross' group discovered that different kinase activators and inhibitors could regulate gap junction assembly at multiple stages in a series of elegant reports; many lab members, especially Dr. Erica TenBroek, were involved in this work. Dr. Lampe would eventually move on to the Fred Hutchison Cancer Research Center where he continues to identify, characterize and assign function to many of the connexin43 phosphorylation events. Further testament to Ross as a gentleman, scholar and mentor was evidenced in 1989 when he reached-out to befriend an unknown new Postdoctoral Fellow, Dr. Dale Laird, at a cell biology meeting in Houston. As collaborators and friends in the years to follow, Dale frequently sought mentorship from Ross in both his professional and personal life.

The 90's brought a new era of discovery for Ross. His 1996 paper in the Journal of Cell Biology solidified the existence and importance of gap junction hemichannels. This highly-cited paper was a rigorous, compelling and extensive study that placed hemichannels clearly on the map. Currently hemichannel studies constitute a large proportion of activity in the field and every Gap Junction Conference since the mid 90's features one or more hemichannel sessions. In addition, with the support of his University of Minnesota zebrafish colleagues, Drs. Perry Hackett and Steve Ekker, Ross continued to expand his research boundaries by turning his attention to the role of connexins in early zebrafish development. This all started when Ross' friend and collaborator, Dr. Jeff Essner, while still a student with Perry, stumbled onto a cDNA clone for Cx43.4. Later Dr. Julia Hatler, while a graduate student in Ross' group, used morpholino approaches to make seminal discoveries evoking Cx43.4 as an essential and evolutionarily-conserved component in left-right patterning of the early vertebrate embryo. Ross' interests in zebrafish connexins brought him together with Dr. Gunnar 
Valdimarsson who some years later died tragically of a brain tumor. Through the zebrafish work of Ross, Gunnar and others, there is little doubt that connexins are at the cornerstone of early development.

In the last few years Ross has returned to freeze-fracture electron microscopy technology. Through his collaboration with Dr. John Rash, they brought the power of freezefracture replica immunolabeling analysis to bear on the assembly problem. Having established a detailed and linear analysis of morphological and mechanistic events that lead to gap junction assembly, Ross and John, along with Drs. Jim Nagy and Alberto Pereda, plan to extend this analysis even further. In 2008, after 40 years at the University of Minnesota, Ross entered phased retirement and together with Esther migrated out west to be close to their two daughters and grandchildren in the San Francisco Bay area close to the beautiful wine country. However, Ross continues to be an active member of the gap junction community. As examples: he spearheaded the successful NIH grant in support of the 2009 IGJC meeting, described recent research findings at the 2011 IGJC meeting in
Belgium, and continues to work on manuscripts and sustain collaborations-all testament to the fact that Ross remains an important and vibrant contributor to the field.

Threaded through Ross's career has been a constant love for and excitement over the science and, more importantly, a love of people and teaching. Whether it is through his mentorship of over $20 \mathrm{PhD}$ students and postdoctoral fellows or his decade as department head or service on graduate student advisory committees at the University of Minnesota ( $\sim 200$ we have learned), Ross has often said how he thoroughly enjoys the people in his life and the life of a scientist. The University of Minnesota feted Ross spectacularly for his retirement, focusing in his honor its annual Developmental Biology Symposium on "The Ties That Bind: Cell Junctions and Adhesion in Development". Now on behalf of the authors of this special issue and the gap junction community in general, we thank you, Ross, for touching all of our lives and we thank you most of all for your friendship. You are unquestionably "one of the really good guys". 